\title{
An Unusual and Previously Unreported Association between Tyrosinemia Type 1 and an Extremely Rare Variation of Congenital Cystic Dilatation: TODANI's VI Cystic Duct Cyst: Report of a Case
}

\author{
Laila Essabar1*, Hajar Rghouda1, Saloua Dahri², Layachi Chabraoui' ${ }^{2}$, Latifa Chat ${ }^{3}$, Yamna Kriouile ${ }^{1}$ \\ ${ }^{1}$ Departement of General Pediatric II-Pediatric Neurology Unit, Rabat Children's Hospital, Rabat, Morocco \\ ${ }^{2}$ Central Laboratory of Clinical Biochemistry, Hospital Ibn Sina, Rabat, Morocco \\ ${ }^{3}$ Departement of Pediatric Radiology, Rabat Children's Hospital, Rabat, Morocco \\ Email: ^laila.essabar@gmail.com
}

How to cite this paper: Essabar, L., Rghouda, H., Dahri, S., Chabraoui, L., Chat, L. and Kriouile, Y. (2016) An Unusual and Previously Unreported Association between Tyrosinemia Type 1 and an Extremely Rare Variation of Congenital Cystic Dilatation: TODANI's VI Cystic Duct Cyst: Report of a Case. Journal of Biosciences and Medicines, 4, 126-131.

http://dx.doi.org/10.4236/jbm.2016.412016

Received: October 11, 2016

Accepted: December 11, 2016

Published: December 14, 2016

Copyright $\odot 2016$ by authors and Scientific Research Publishing Inc. This work is licensed under the Creative Commons Attribution International License (CC BY 4.0). http://creativecommons.org/licenses/by/4.0/

\begin{abstract}
Cystic duct cysts are rare lesions, and type VI of TODANI's modified classification is the rarest subtype with only sporadic case reports in the literature. The following report describes the coexistence of this entity and type 1 tyrosinemia in a one monthold infant referred to our department for etiological investigations of prolonged neonatal cholestasis. To the best of our knowledge, we report herein the first case in the literature describing this association. Cystic duct abnormalities should be considered in the differential diagnosis of neonatal cholestases, however further investigations should be performed to exclude associated life-threatening conditions such as metabolic disorders including tyrosinemia.
\end{abstract}

\section{Keywords}

Cystic Duct, Choledochal Cyst, Tyrosinemia, Cholestasis, NTBC, Neonate

\section{Introduction}

Congenital cystic dilatation of the extrahepatic biliary tree is a relatively unusual condition [1]. Cystic dilatation of the cystic duct is an extremely rare variant, only sporadic case reports are documented in the literature [2].

This entity was initially not included in TODANI classification, the most accepted classification system of biliary cysts, and was subsequently categorized as type VI [3] [4]. 
We present an unusual and previously unreported association between TODANI's VI cystic duct cyst and tyrosinemia type 1, an inborn error of tyrosine metabolism with severe disruption of intracellular metabolism of the liver and kidney [5].

\section{Case Report}

A one month-old male patient was born at term to non consanguineous parents by dystocic vaginal delivery; his birth weight was $2400 \mathrm{~g}$. Jaundice appeared at birth with dark urine and intermittent pale yellow stools. The patient was first treated for bacterial maternofetal infection in regional neonatal centre then referred to our department for prolonged neonatal jaundice.

General physical examination revealed growth failure with marked microcephaly and overlapping of the skull bones; mild jaundice and axial hypotonia; there were no dysmorphic features. Abdominal examination was unremarkable. Ophtalmic exam yielded convergent squint with loss of visual fixation and pursuit; fundoscopic examination disclosed bilateral chorioretinal atrophy with a highly significant decrease in retinal activity in the visual electrophysiological tests.

Laboratory tests showed the following abnormalities: total bilirubin value was 152 $\mathrm{mg} / \mathrm{l}$; direct bilirubin level was $98 \mathrm{mg} / \mathrm{l}$; alkaline phosphatase $355 \mathrm{IU} / \mathrm{l}$; serum glutamic oxaloacetic transaminase (SGOT) 589 IU/l; serum glutamic pyruvic transaminase (SGPT) $328 \mathrm{IU} / \mathrm{l}$, and c-glutamyltranspeptidase $63 \mathrm{U} / \mathrm{l}$. Prothrombin ratio was $60 \%$; coagulation factor $\mathrm{V}$ was $137 \%$.

Diagnosis of TORSCH infections, hypothyroidism, galactosemia, Alagille syndrome, urinary tract infection was ruled out. Alfa-fetoprotein was $6541 \mathrm{ng} / \mathrm{mL}$; serum amino acids showed elevated tyrosine; urine Succinyl acetone was $85 \mu \mathrm{mol} / \mathrm{L}$ (normal value $<10$ $\mu \mathrm{mol} / \mathrm{L})$. In addition, there were no signs of renal dysfunction or rickets.

Abdominal ultrasonography disclosed cystic dust cyst type VI of TODANI's modified classification without liver or spleen enlargement. Abdominal CT scan revealed the same findings (Figure 1) with multiple stones within the dilated portion of the cystic duct and the gallbladder. The intrahepatic ducts were slightly dilated while pancreatic duct appeared normal. Cerebral CT scan revealed multicystic encephalomalacia with marked cerebral atrophy and overlapping of the cranial bones (Figure 2).
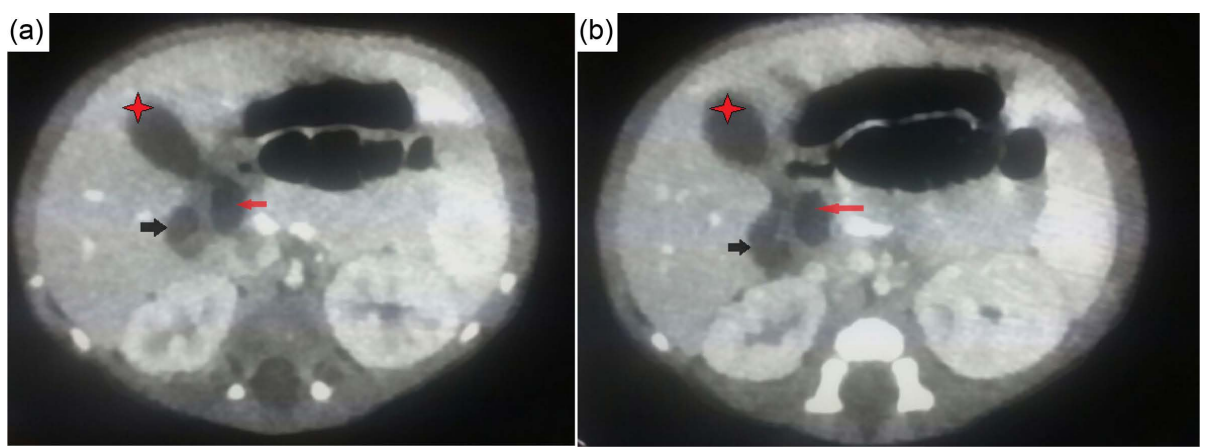

Figure 1. Axial contrast-enhanced abdominal CT images show cystic dilatation of the cystic duct (black arrows), dilated extrahepatic duct (red arrows) and the gallbladder (asterisk). 


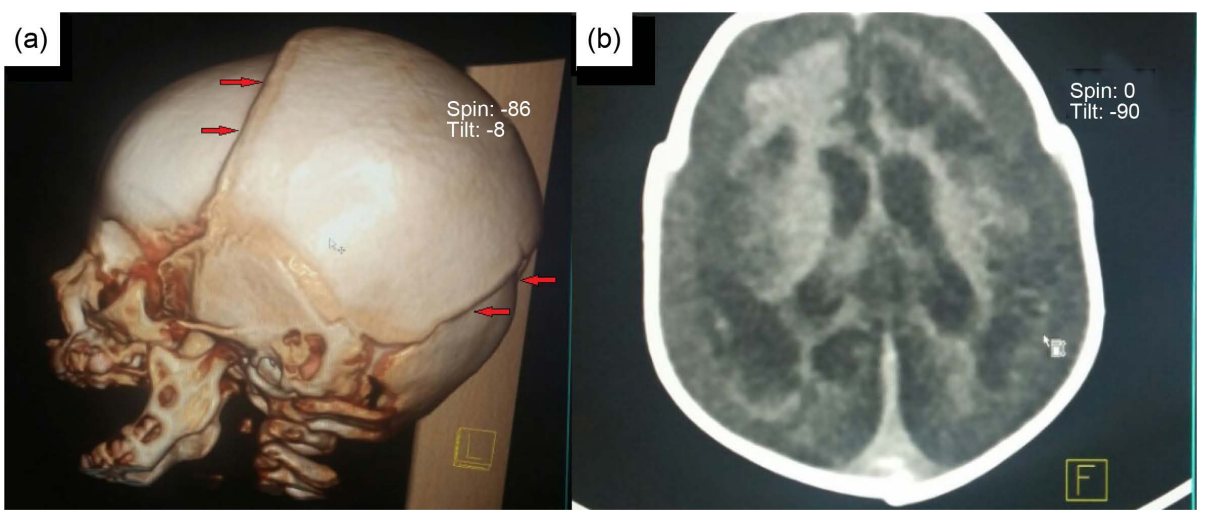

Figure 2. Cerebral CT scan: (a) Lateral view of 3D reconstruction shows overlapping of the skull bones (arrows); (b) axial contrast-enhanced image shows multiple cystic encephalomalacia.

These findings were reported as being consistent with association between tyrosinemia type 1 and cystic duct cyst type VI of TODANI's classification. Genetic testing is ongoing.

Treatment management was based on NTBC therapy as well as nutritional measures, fat-soluble vitamins supplementation and ursodeoxycholic acid. Surgery was postponed.

At two-month follow-up, jaundice had regressed; liver function tests normalized, coagulation tests remained correct and Alfa-fetoprotein level had significantly decreased from 6541 to $63 \mathrm{ng} / \mathrm{mL}$.

\section{Discussion}

Isolated cystic duct cyst is extremely rare, an extensive literature review found only sporadic case reports [2].

The most accepted classification, by Todani et al. [6], includes five different types of biliary cyst. Subsequently, cystic dilatation of the cystic duct were added and described as "type VI lesions" [7].

The absolute etiology of cystic duct cysts remains elusive, although theories have been proposed including congenital cystic duct stricture and proximal ductal dilatation, or an associated functional abnormality and absence of ganglion cells in choledochal and cystic duct dilatation [8].

Symptoms often differ according to the age of the patient. Adults commonly present with abdominal pain related to biliary or pancreatic obstruction, whereas children commonly present with jaundice [9].

The current patient presented with jaundice; as two causes for cholestases coexisted, it was difficult to specify whether jaundice was secondary to both of these conditions or tyrosinemia only. The latter seems more likely given the late age of onset described in all reported cases of type VI cystic duct dilatations. Furthermore, jaundice and liver tests improvement within two months of starting NTBC therapy was consistent with this belief.

Diagnosis of type VI cystic duct cysts may be difficult; interestingly, most of authors 
mistakenly made a preoperative diagnosis of type II choledochal cyst or Mirizzi's syndrome [7] [8]. Radiological evaluation, especially with MRCP, is critical for the correct pre-operative diagnosis and treatment plan [8].

Surgical excision is the treatment of choice considering the risk of recurrent cholangitis, acute biliary colic, pancreatitis [7]; as well as malignant degeneration [9], the degenerated mucosa of a choledochal cyst increases the risk for carcinomatous development due to chronic irritation, ulceration and subsequent regeneration of cyst epithelium [10]. In our patient, the coexistence of tyrosinemia and cystic duct cyst, two conditions with risk of cancer, requires carefulness.

The recommended surgical treatment for cystic dilatation of the cystic duct is cholecystectomy with excision of the cyst and transection of the cystic duct [1] [4].

If there is a wide opening between the cystic duct and common duct, Rouxen-Y choledochal jejunostomy and total cyst excision are required [7].

In the other hand, type I tyrosineamia is a rare inborn error of tyrosine metabolism characterized by progressive liver disease, increased risk of hepatocellular carcinoma, neurological crises and renal tubular dysfunction. In acute type, hepatic insufficiency develops before six months of age as a result of cirrhosis. In subacute type however, hepatomegaly, irregular bleeding and rickets are observed after six months. Chronic type manifests itself with hepatomegaly, rickets and growth retardation after one year of age [11]. As patients are often asymptomatic in the first few months of life and the initial clinical symptoms are rather unspecific newborn screening is mandatory to diagnose patients early in life [12]. Recent studies have shown this [12]: Newborn screening is best performed using succinylacetone as a primary marker because it is sensitive and specific. Blood spot tyrosine is neither specific nor sensitive [13]. As the newborn screening programme for tyrosinaemia type 1 is not available in our country, our patient presented clinically with mild jaundice without bleeding, hepatomegaly, or renal disease. Liver function tests were moderately disturbed.

The characteristic renal disease is a tubular disorder with a Fanconi syndrome; the typical features include aminoaciduria, glycosuria, phosphaturia, renal tubular acidosis and hypophosphataemic rickets [5]. None of these abnormalities was found in our case.

There may also be a 10 - 15 fold increase in the serum AFP level. An abrupt increase in serum AFP is a red flag for detection of hepatocellular carcinoma [11]. Our patient had very high AFP level but abdominal CT showed no evidence of nodular lesions.

Succinylacetone, the actual toxic substance in tyrosinemia type $\mathrm{I}$, is responsible for liver and kidney pathologies. This toxic substance accumulation is prevented by nitisinone also known as NTBC (2-(2-nitro-4-trifluoromethylbenzoyl)-1,3-cyclohexane-dione). In line with many studies [14] [15], S. Mayorandan et al. have found that patients who received NTBC-treatment later, had a 2-12-fold higher risk (depending on age at start of therapy) of developing hepatocellular carcinoma compared to patients treated as neonates.

Through the initial findings of clinical, biological and radiological examination, the diagnosis was established as cystic duct cyst. However, the alarmingly high levels of 
AFP, the deranged liver function parameters, and the elevated levels of serum tyrosine provided key for the diagnosis coexisting tyrosinemia type 1, further strengthened by the increase in urinary excretion of succinylacetone. The definitive confirmatory test for tyrosinemia is demonstration of low enzyme in fresh liver biopsy or by identification of a disease causing mutation on DNA study [11]. Our patient underwent a genetic testing, the result is ongoing.

Despite considerable progress in the diagnosis and management of patients with tyrosinemia type 1 in the last 20 years there is lack of a guideline. A review of the literature revealed only few regional studies [16] [17]. Treatment involves phenylalanine and tyrosine limited diet prescription. Another treatment modality is the use of NTBC, which are strong inhibitors of 4-hydroxyphenylpyruvate dehydrogenase involved in the second step of tyrosine metabolism [11]. Liver transplantation is the treatment of last resort when patients fail to respond To NTBC therapy or develop hepatocellular cancer [12].

Our patient received NTBC with phenylalanine- and tyrosine-free formula as well as chronic cholestasis symptomatic measures.

In summary, work up for neonatal cholestasis in the presented case was suggestive of two rare different entities. To the best of our knowledge this is the first case in the literature describing an association between type VI cystic duct cyst and type 1 tyrosinemia.

\section{Conclusion}

Although coexistence of two causes for cholestases is very rare, as clinicians, we need to look beyond biliary ducts abnormalities and consider the possibility of co-existing entities like metabolic disease including tyrosinemia.

\section{Conflict of Interest}

None declared.

\section{References}

[1] Bode, W.E. and Aust, J.B. (1983) Isolated Cystic Dilatation of the Cystic Duct. The American Journal of Surgery, 145, 828-829. https://doi.org/10.1016/0002-9610(83)90152-6

[2] Conway, W.C., Telian, S.H., Wasif, N. and Gagandeep, S. (2009) Type VI Biliary Cyst: Report of a Case. Surgery Today, 39, 77-79. https://doi.org/10.1007/s00595-008-3789-4

[3] Dumitrascu, T., Lupescu, I. and Ionescu, M. (2012) The Todani Classification for Bile Duct Cysts: An Overview. Acta chirurgica Belgica, 112, 340-345. https://doi.org/10.1080/00015458.2012.11680849

[4] Serena Serradel, A.F., Santamaria, L.E. and Herrera, G.R. (1991) Cystic Dilatation of the Cystic Duct: A New Type of Biliary Cyst. Surger, 109, 320-322.

[5] de Laet, C., Carlo, D.V., James, V.L., et al. (2013) Recommendations for the Management of Tyrosinaemia Type 1. Orphanet Journal of Rare Diseases, 8,8 . https://doi.org/10.1186/1750-1172-8-8

[6] Todani, T., Watanabe, Y., Nanisue, M., et al. (1977) Congenital Bile Duct Cysts: Classification, Operative Procedures, and Review of Thirty-Seven Cases Including Cancer Arising 
from Choledochal Cyst. The American Journal of Surgery, 134, 263-269.

[7] Loke, T., Lam, S. and Chan, C. (1999) Choledochal Cyst: An Unusual Type of Cystic Dilatation of the Cystic Duct. American Journal of Roentgenology, 173, 619-620.

https://doi.org/10.2214/ajr.173.3.10470889

[8] Yoon, J.H. (2011) Magnetic Resonance Cholangiopancreatography Diagnosis of Choledochal Cyst Involving the Cystic Duct: Report of Three Cases. British Journal of Radiology, 84, 18-22. https://doi.org/10.1259/bjr/77844300

[9] De Vries, J.S., de Vries, S., Aronson, D.C., Bosman, D.K., Rauws, E.A., Bosma, A., et al. (2002) Choledochal Cysts: Age of Presentation, Symptoms, and Late Complications Related to Todani's Classification. Journal of Pediatric Surgery, 37, 1568-1573.

https://doi.org/10.1053/jpsu.2002.36186

[10] Todani, T., Tabuchi, K., Watanabe, Y. and Kobayashi, T. (1979) Carcinoma Arising in the Wall of Congenital Bile Duct Cysts. Cancer, 44, 1134-1141. https://doi.org/10.1002/1097-0142(197909)44:3<1134::AID-CNCR2820440350>3.0.CO;2-T

[11] Rashad, M.M. and Nassar, C. (2011) Tyrosinemia Type 1: A Case Report. Sudanese Journal of Paediatrics, 11, 64-67.

[12] Mayorandan, S., Meyer, U., Gokcay, G., Segarra, N.G., et al. (2014) Cross-Sectional Study of 168 Patients with Hepatorenal Tyrosinaemia and Implications for Clinical Practice. Orphanet Journal of Rare Diseases, 9, 107. https://doi.org/10.1186/s13023-014-0107-7

[13] Sander, J., Janzen, N., Peter, M., Sander, S., Holtkamp, U., Schwahn, B., Mayatepek, E., Trefz, F.K. and Das, A.M. (2006) Newborn Screening or Hepatorenal Tyrosinemia: Tandem Mass Spectrometric Quantification of Succinylacetone. Clinical Chemistry, 52, 482-487. https://doi.org/10.1373/clinchem.2005.059790

[14] Baumann, U., Preece, M.A., Green, A., Kelly, D.A. and McKiernan, P.J. (2005) Hyperinsulinism in Tyrosinaemia Type I. Journal of Inherited Metabolic Disease, 28, 131-135. https://doi.org/10.1007/s10545-005-5517-1

[15] Van Spronsen, F.J., Thomasse, Y., Smit, G.P., Leonard, J.V., Clayton, P.T., Fidler, V., Berger, R. and Heymans, H.S. (1994) Hereditary Tyrosinemia Type I: A New Clinical Classification with Difference in Prognosis on Dietary Treatment. Hepatology, 20, 1187-1191. https://doi.org/10.1002/hep.1840200513

[16] Masurel-Paulet, A., Poggi-Bach, J., Rolland, M.O., Bernard, O., et al. (2008) NTBC-Treatment in Tyrosinaemia Type I: Long-Term Outcome in French Patients. Journal of Inherited Metabolic Disease, 31, 81-87. https://doi.org/10.1007/s10545-008-0793-1

[17] Coskun, T., Ozalp, I., Kocak, N., Yüce, A., Caglar, M. and Berger, R. (1991) Type I Hereditary Tyrosinaemia: Presentation of 11 Cases. Journal of Inherited Metabolic Disease, 14, 765-770. https://doi.org/10.1007/BF01799947 
Submit or recommend next manuscript to SCIRP and we will provide best service for you:

Accepting pre-submission inquiries through Email, Facebook, LinkedIn, Twitter, etc. A wide selection of journals (inclusive of 9 subjects, more than 200 journals)

Providing 24-hour high-quality service

User-friendly online submission system

Fair and swift peer-review system

Efficient typesetting and proofreading procedure

Display of the result of downloads and visits, as well as the number of cited articles

Maximum dissemination of your research work

Submit your manuscript at: http://papersubmission.scirp.org/

Or contact jbm@scirp.org 